\title{
The Interplay of Identity and Social Network: A Methodological and Empirical study*
}

\author{
Anirban Ghatak ${ }^{\dagger}$ Abhishek Ray ${ }^{\ddagger}$ and Diganta Mukherjee ${ }^{\S}$
}

September 23, 2016

\section{Introduction}

Let us start this paper by considering a typical scene in a bus in India. Let us assume there are 4 empty seats in the bus when a person got into it. Among those 4 seats, one is beside a young middle class girl, one is beside an old lower class woman, one is beside a middle aged nicely dressed man and another is beside a poor old man. While all of these characteristics are almost surely conceivable from the appearances of those persons mentioned, where would the person, who just got in, will choose to sit? Our experience and the knowledge built upon the daily experience of bus commuters in India suggests that there is a very specific pattern of choosing such a seat. The pattern of such choice seems to be intricately connected to the identity of the person who will be making the choice. This pattern of choice when multiple options relating to any kind of connection with human beings are concerned is not only observable in this situation, if we observe a group of students in a school or college, we see certain conglomerations even before they become friends. If we take a keen look at the spatial distribution of caste and religion in cities and villages, we see a certain stable aggregation is achieved after settlement.

We are fascinated about the root of such choices that determine our friends, neighbors, acquaintances, seatneighbors, business partners, protégés and so on. We hypothesize that the identity of the chooser is the most important factor towards deciding on a connection to be established with another human being. We also believe that the relationship between identity and network of a human being is not only one way, rather it works both ways where the existing and future filiative or affiliative networks of a human being also determine the person's present and future identity. To examine if such a relationship exists, in this paper we study the relationship between human activity of networking and its identity through an extensive survey.

We posit our argument through the trope of the sociological concept of "Cultural Capital" (Bourdieu, 2011) which is the qualitative characteristics of a human being that enables the person to access certain amenities provided by the society. Religion, race, caste, gender, sexuality, educational level, economic level, and all such characteristics of a person's identity contributes to the person's cultural capital that enables a person to be in a certain agentive position in the society. According to Bourdieu, cultural capital can be embodied, objectified or institutionalized. We are concerned about the embodied cultural capital in building our argument. The

\footnotetext{
${ }^{*}$ We thank the Government of West Bengal for a project grant which made the survey possible. We are grateful to the students and scholars who meticulously executed the survey for us. A special thanks goes to Dr. Nandita Dhawan for critical help in organising the survey and to Ms Malabika Biswas for her critical inputs regarding the sociology scholarship. The workshop participants at IIT Ropar and IGIDR Mumbai has contributed to the work at its various formative stages with comments and suggestions. The usual caveat applies.

${ }^{\dagger}$ Welingkar Institute of Management Development \& Research, Mumbai, Email: aghatak@gmail.com

¥Indian Statistical Institute, Kolkata, Email: abhishekraymath@gmail.com

$\S$ Indian Statistical Institute, Kolkata, Email: diganta@isical.ac.in
} 
embodied form of cultural capital is not a static identifier of a person. A person can acquire cultural capital through various means of 'self-development'.

Most of the properties of cultural capital can be deduced from the fact that, in its fundamental state, it is linked to the body and presupposes embodiment. The accumulation of cultural capital in the embodied state, i.e., in the form of what is called culture, cultivation, Bildung, presupposes a process of embodiment, incorporation, which, insofar as it implies a labor of inculcation and assimilation, costs time, time which must be invested personally by the investor. (Bourdieu, 2011)

Cultural capital and economic capital gives birth to another kind of capital that is "Social Capital' (Bourdieu, 2011; Coleman, 1988). Social capital, according to Bourdieu is "...the aggregate of the actual or potential resources which are linked to possession of a durable network of more or less institutionalized relationships of mutual acquaintance and recognition - or in other words, to membership in a group - which provides each of its members with the backing of the collectively-owned capital, a 'credential' which entitles them to credit, in the various senses of the word." Thus, the appropriation of social capital enables oneself to aim for another network or institution that embodies even more resource and hence, increases the person's cultural capital. We hypothesize that the activity of network building observed in human beings is entirely driven by the urge of acquiring cultural capital through "a durable network of more or less institutionalized relationships of mutual acquaintance and recognition". Moreover, once the person is assured of the membership of the institutionalized network, that membership in turn increases further opportunities for enhancing the person's cultural capital. We believe that the process of human network building continues through this route of appropriation and reappropriation of cultural capital through building one's own network.

The concept of Cultural Capital has been widely used in various disciplines of social sciences and humanities, as a theoretical tool to investigate and define various locations of sociocultural and political marginalization within the power structure. For example, studies have been done on how Cultural Capital plays a crucial role in the domain of education system (Emirbayer and Williams, 2005; Stanton-Salazar and Dornbusch, 1995; Dumais, 2002; Emmison and Frow, 1998; Sullivan, 2001; DiMaggio, 1982; De Graaf et al., 2000; Harker, 1990). Sometimes, the concept of Cultural Capital has also been critiqued for its deterministic nature (King, 2000; Goldthorpe, 2007). However, whereas Cultural Capital, as a theoretical tool of defining identity, talks extensively about its relation with other forms of capital, especially Economic Capital, it has been little used in Economics as a defining tool of socioeconomic relationship in a society, though the use of the term Cultural Capital has been exported to Economics with varied connotations (Fryer, 2003; Throsby, 1999). Social capital, that gets enabled by cultural capital and economic capital is the ability of individuals or groups to access resources that are indigenous to their network. Social capital can give birth to other forms of capital such as human capital in terms of favor or intellectual capital in terms of new information or expansion of knowledge (Resnick, 2001). Lin et al. (2001) defines social capital as "investment in social relations with expected returns in the marketplace". According to this framing, social capital is created through the interactions in the social networks a person creates and the expectations of the future resources that the network embeds in itself. Social capital can be of two types, "bridging" and "bonding" (Putnam, 2000; Williams, 2006). Bridging capital is often associated with the ties which connect two different clusters in a network which felicitates propagation of novel information (Burt, 2009). Bonding capital, on the other hand are generated by strong ties within a cluster through repetitive interaction and that is characterized with higher levels of trust, support and intimacy. Weaker ties (such as a friend of a friend) are more likely to be bridging ties and thus provide access to novel information (Granovetter, 1973) and diverse perspectives (associated with bridging social capital). We deal with both types of ties here in the terms of filial and affilial relationships. The cultural capital acquired through filial ties, we assume, are either impossible or tough to change, and the utility acquired from such ties remains more or less constant. On the other hand, the affilial ties are the ones which a person can choose in order to maximize the cultural capital of one's own.

While the identity of human beings can have various meanings based on the context of discussion, we try to collate every single identifier of a human being to form its identity, as a specific and unique identifier of its self. These can be religious identity, caste identity, economic identity, professional identity, historical identity, 
gender identity, sexual identity and many more such identities describing a human's current and previous states of being. Our notion of identity combines every such identities together to form any individual's "Identity vector" of which each identity mentioned earlier will be a member. The identity vector will be used to identify each individual in order to find out if there is any specific observable and testable pattern of connecting to other people with respect to that identity, or any of its variables. Our model of using identities to explain social and economic activities takes its cue from Akerlof and Kranton (2000). We have modified their model in order to facilitate the trope of cultural capital through which we build our model of utility accumulation by means of strategic network building.

We chose to observe the network that forms around any human being due to its past and present being, through its familial ties, societal relationships, personal relationships and professional acquaintance. The people an individual connects to during all such either obligatory or strategic environments make its network. We record the nature of this network through the perception of the individual around whom the network is developed in order to find out the revealed preferences of the individual while connecting to other people in its life. We also record the identity characteristics of each member of the individual's network, as observed by the individual concerned. Thus, we find out the identity categories that remain unknown to the individual about a member of its network, reveals the awareness level regarding to that specific identity category. For example, if we find that an individual does not know the caste of its close friend, we derive that caste was not instrumental in sustaining that particular edge of its friendship network. We also look at certain 'openness' feature observed through the networks. We observe the character of a person's network and create a metric of the person's openness based on the number of persons dissimilar with its self. We will discuss more about the construction of these metrics later. We observe a number of individuals from various strata of the society to gather the data of their networks and the identities of the members of those networks as perceived by them. The revealed preferences regarding the decisions of their strategic connections combined with their own identity variables enable us to find a definite linkage between identities and the conscious choice of agents in one's network.

The plan of the paper is as follows. In the next section the theoretical and empirical formulation of the problem is presented. The background details of our primary survey is discussed in Section 3. Section 4 presents the results of our empirical analysis and relevant discussion.

\section{Survey Details}

Our survey was carried out during the months of November 2014 to June 2015. We had surveyed a total of 191 individuals spread over various social and economic strata. The respondents of our survey were mostly located in and around Kolkata, India primarily for the economic and locational feasibility as the surveyors and the researchers both were based in Kolkata. We consciously tried to achieve as much variation as possible in the social, economic and cultural backgrounds of the people surveyed in our sample in order to maximize the diversity in the pool of identities we gather to observe their behavior.

We had adopted a two tier sampling scheme where in the initial phase we had divided our target population into various strata and then within those strata, we did either a simple random sampling or a snowball sampling. We had stratified our population based primarily on their occupation. The strata those we had identified before doing a random sampling within them were i) University student, ii) University teaching staff, iii) University non-teaching staff, iv) Information Technology sector workers (white collar), v) Industrial blue collar workers, vi) Industrial white collar workers, vii) Unorganised sectors' workers, viii) Beauty workers (both employed and self-employed), ix) Sex workers, x) People with non-normative sexuality (Lesbian/Gay/Bisexual/Transsexual LGBT), xi) Auto Rickshaw drivers, and xii) Cycle Rickshaw drivers.

We had adopted a snowball sampling method for sampling from the sex workers and the LGBT population due to their constitutionally unrecognized existence in the society, while the rest were sampled by the method of simple random sampling. 
Our respondents, who were randomly selected from the various strata mentioned earlier, were asked a set of questions regarding their various categories of identities like religion, caste, gender, sexuality, language, income, educational background, migration history, parents' details and so on. They were also asked the same questions regarding their spouse (if any), children (if any), siblings (if any), and five most important persons in each of the three affiliative networks 'Friends', 'Colleagues', and 'Neighbors' to have an idea about the identity of the agents that is formed centering the respondent. In this way, we got information about the various identities of 191 persons and their knowledge about the identities of their network consisting of 2305 persons.

Below we provide a detailed descriptive statistics table based on two dimensional groupings $(Y, G)$ which would help us in understanding the basic features of our sample.

\begin{tabular}{|l|c|c|c|c|c|}
\hline Characteristic & $(0,0)$ & $(0,1)$ & $(1,0)$ & $(1,1)$ & Total \\
\hline Total no of observations & 41 & 65 & 19 & 53 & 178 \\
Married & 12 & 41 & 12 & 45 & 110 \\
Single/Separated & 29 & 24 & 7 & 8 & 68 \\
have children & 18 & 40 & 9 & 42 & 109 \\
do not have children & 23 & 25 & 10 & 11 & 69 \\
Total Children & 89 & 121 & 14 & 73 & 297 \\
Avg Children & 2.17 & 1.86 & 0.74 & 1.38 & \\
Total Sibling & 119 & 141 & 30 & 89 & 379 \\
Avg Sibling & 2.90 & 2.17 & 1.58 & 1.68 & \\
Total Friends & 108 & 140 & 32 & 163 & 443 \\
Avg Friends & 2.63 & 2.15 & 1.68 & 3.08 & \\
Total Neighbour & 97 & 148 & 59 & 150 & 454 \\
Avg Neighbour & 2.37 & 2.28 & 3.11 & 2.83 & \\
Total colleague & 77 & 124 & 57 & 150 & 408 \\
Average Colleague & 1.88 & 1.91 & 3.00 & 2.83 & \\
\hline
\end{tabular}

Table 1: General Descriptives of the Sample

From the above descritive statistics table, we can see that high income $(Y)$ individuals rep[ort more neighbours and colleagues on average. Also, the highest combination $(1,1)$ reports the highest number of friends. The lowest conbination $(0,0)$ has the lowest married rate $(<30 \%)$ but highest number of children (among relevant subset) and siblings. They are followed by $(0,1)$. This seems natural as lower income individuals tend to have larger families.

\section{Openness and other Indicators}

In this section we will define the theoretical background that we use to find the relationship between identity and network formation. Using the data on the person's Caste, Income, Religion, and Gender, one of our primary interests will be to know if a person mingles more in its own group according to these four categories, or is more 'open' in its social behaviour.

\subsection{Utility Formulation}

Even though numerous social/ economic categories may inform regarding a person's identity profile; due to the practical constraints on th size of our survey, we restrict ourselves to only a few of them to enable significant statistical analyses. Thus, in this paper, social Categories considered are Religion, Caste and Gender. Let there be two religions, three castes and two genders (for the sake of simplicity as well as parametric burden considerations). 
The category sets are thus $R=\{0,1\}, C=\{0,1,2\}, G=\{0,1\}$. In addition we also consider four income categories $Y=\{0,1,2,3\}$.

To formulate the utility when $i$ is to connect with $j$ let us propose

$$
U^{i j}=U(\text { flocking, preferential attachment })
$$

and for analytical simplicity, we further specialise to a strictly separable form,

$$
U^{i j}=U_{c}^{i j}+g U_{s}^{i j}
$$

Here $U_{c}^{i j}=$ Utility derived from community strength and $U_{s}^{i j}=$ Utility derived from social status; and the rate of substitution between the community strength component and the status component fixed at $U_{c}: U_{s}:: 1: g$.

We formulate $U_{c}$ as a simple linear form

$$
U_{c}^{i j}=m I_{Y}+n I_{G}+p I_{C}+q I_{R}
$$

where $I_{Y}, I_{G}, I_{C}$ and $I_{R}$ are indicator variables for matching subscripts in $Y, G, C$ and $R$ respectively. And $U_{s}$ as a cobb-Douglas type utility with prescribed degrees of substitutability among the categories

$$
U_{s}^{i j}=m^{\alpha_{Y}} \times n^{\alpha_{G}} \times p^{\alpha_{C}} \times q^{\alpha_{R}},
$$

where $\alpha_{K}=\operatorname{argdifference}_{K}\left(i_{K}-j_{K}\right)$. We assume the weight proportion between the categories as $Y: G: C$ : $R:: m: n: p: q$, where $m, n, p, q>0$ are the parameters of our model, to be estimated.

\subsection{Indicators}

To perform the relevant tests based on the data we frame our variables as follows.

We start with labelling the identity categories caste, income, religion, and gender as 1,2, 3, and 4 .

We create some qualitative response variables like $I_{j}^{i=1}=G C, S C, S T, O B C$. , where $i=1$ denotes the category caste and $j$ the person concerned. We create similar variables for each category.

Now, define

$$
d_{j l}^{i=1}=\left\{\begin{array}{l}
0 \text { if } I_{j}^{i=1}=I_{l}^{i=1} \\
1 \text { otherwise }
\end{array}\right.
$$

Then the unscaled measure of openness is put forward as

$$
M_{j}^{i=1}=\sum_{l} d_{j l}^{i=1}
$$

We also get the following variables from the data collected through the survey (details follow):

$$
\begin{gathered}
F_{j}=\text { Total number of friends reported by the person } j \\
N_{j}=\text { Total number of neighbours reported by the person } j \\
C_{j}=\text { Total number of colleagues reported by the person } j
\end{gathered}
$$

From these variables, we compute $\operatorname{Total}_{j}=F_{j}+N_{j}+C_{j}$. Now the openness index for the person $j$ with respect to caste can be defined as

$$
O_{j}^{i=1}=\frac{M_{j}^{i=1}}{\text { Total }_{j}}
$$

Clearly this 'openness' index lies within 0 and 1. 
In the next step, we build an awareness index for our analysis. We create the following indicator variables for the person $j$ and one of his aquaintances $k$.

$$
\begin{aligned}
& A_{j k}^{i=1}=\left\{\begin{array}{l}
1 \text { if } \mathrm{j} \text { knows the caste of } \mathrm{k} \text { and } \\
0 \text { otherwise }
\end{array}\right. \\
& A_{j k}^{i=2}=\left\{\begin{array}{l}
1 \text { if } \mathrm{j} \text { knows the income of } \mathrm{k} \text { and } \\
0 \text { otherwise }
\end{array}\right. \\
& A_{j k}^{i=3}=\left\{\begin{array}{l}
1 \text { if } \mathrm{j} \text { knows the religion of } \mathrm{k} \text { and } \\
0 \text { otherwise }
\end{array}\right.
\end{aligned}
$$

Then, $A_{j}^{i=1}=\sum_{k=1}^{N} A_{j k}^{i=1}, A_{j}^{i=2}=\sum_{k=1}^{N} A_{j k}^{i=2}$ and $A_{j}^{i=3}=\sum_{k=1}^{N} A_{j k}^{i=3}$.

So an overall awareness index for person $j$ with respect to caste can be

$$
a_{j}^{i=1}=\frac{A_{j}^{i=1}}{\text { Total }_{j}}
$$

Comparison between the 'openness index' of different groups from the each of the categories Caste, Income, Religion and Gender can be done using the Kolmovorov-Smirnoff test. As the test is a non-parametric test, one does not need a prior assumption about the distribution.

Thus the comparisons can be done between $O_{j=G C}^{i=1}, O_{j=S C}^{i=1}$ and $O_{j=S T}^{i=1}$ using the test statistic. Log-odds ratio is to be used for constructing the test statistic. Also, as we have defined the distance function $d$ we can define the relative distance function $R d$ as follows:

$$
\left.R d_{j l}^{i=1}\right|_{j=S C}=\left\{\begin{array}{l}
0 \text { if } I_{l}^{i=1}=G C \text { or } S C \\
1 \text { otherwise }
\end{array}\right.
$$

Then relative openness can be formulated as:

$$
R O_{j=S C}^{i=1}=\frac{\left.\sum_{l} R d_{j l}^{i=1}\right|_{j=S C}}{\text { Total }_{j}}
$$

and likewise for other categories. Here also the log-odds ratio can be used for performing the non-parametric tests.

For the purpose of statistical analysis, we assume that the resulting utility $U^{i j}$ is perceived by individuals with some randomness. Thus we postulate that

$$
U^{i j}=U(\text { flocking, preferential attachment })+\text { random component }
$$

In terms of the above discussion, if $O_{j}^{i=1}$ denotes the openness index of the $j^{\text {th }}$ person with respect to the $1^{\text {st }}$ character, then $\left(1-O_{j}^{i=1}\right) \propto U$ (flocking) and $O_{j}^{i=1}$ consists of two parts, one of which is the preferential attachment part, and the other is the random behaviour of the individual.

\section{Survey Results \& Discussion}

We had hypothesized that identity of an individual is essential and decisive in the formation of the network that the person builds around itself. We have restricted our primary analysis within four main identity category: caste, religion, gender, and economic class (income group). We begin with some discussion on the connection 
propensities of the individuals belonging to different identity categories. As there are some missing data problems for "caste" and less number of non-hindu respondents, we begin our discussion by providing propensity details in terms of two dimensional (income and gender) identity categories. The table below shows the basic connection data.

\begin{tabular}{|l|c|c|c|c|c|c|}
\hline & & \multicolumn{5}{|c|}{ Connects with: number (percentage) } \\
identity & number & $(0,0)$ & $(1,0)$ & $(0,1)$ & $(1,1)$ & Total \\
\hline$(0,0)$ & 41 & $295(56.5)$ & $136(26.1)$ & $27(5.2)$ & $64(12.3)$ & 522 \\
$(1,0)$ & 65 & $30(14)$ & $13(6.1)$ & $75(35)$ & $96(44.9)$ & 214 \\
$(0,1)$ & 19 & $156(31.6)$ & $7(1.4)$ & $298(60.3)$ & $33(6.7)$ & 494 \\
$(1,1)$ & 53 & $102(19.7)$ & $61(11.8)$ & $61(11.8)$ & $295(56.8)$ & 519 \\
\hline Total & 178 & & & & & 1749 \\
\hline
\end{tabular}

Table 2: Two dimensional Connection Propensities

From the above table it seems that homogamy is a dominant trait for the (two dimensional) groups under consideration. Three out of four shows homogamy as the dominant trait, except $(1,0)$. Among the two dimensions considered, Income and Gender, the preference ordering is revealed for two of the groups. For $(0,0)$, the revealed preference is Gender and then Income. For the group $(0,1)$ this is reversed.

We have adopted two statistical tests to find out if the measure of 'openness' varies over different identity of a single identity category. We have done (a) Kolmogorov-Smirnoff Test, and (b) Regression in order to find if there is any compelling evidence to believe that the network formed around any person is actually decided and controlled by the person's identity.

In Kolmogorov - Smirnoff tests we wanted to check if there is any compelling evidence for believing if the openness coefficient for a specific identity category varies over two sub-populations of the same identity category. Eg., whether in caste parameter, the openness of the 'General Caste' differs from that of the 'Other Castes'. The test basically checks disparity between the two empirical distribution functions. Based on which it reports whether the two sample comes from the same distribution or not. We interpret the result of the tests by looking at the magnitude of the $\mathrm{p}$-value. If $p<0.05$ then there is compelling evidence that the two distributions are different.

We have done the test of regression to see how the openness depends on one's religion, caste, income group and gender. In other words, the test of regression tells us how the 'openness' index of different category varies over the sub-populations of every category. Eg. how the caste openness varies over gender can be observed from this test. There are four types of openness, religion, caste , income group and gender. Thus there will be four regressions, each with 4 independent variables. As the dependent variables are categorical, we make a suitable log ratio transformation and then run the linear regression. The sign of the coefficients will determine the direction of relationship. The $R^{2}$ value gives an idea of the quality of regression performance.

The Kolmogorov-Smirnoff test results (Table 3) show that

1. The caste openness between people of general caste and people of other castes varies significantly

2. The gender openness between people who are male and people who are of other gender identities varies extremely significantly

3. The religion openness test could not be done because we did not find sufficient number of non-hindu respondents to reasonably carry out the test

4. The economic status openness between people of various income levels does not vary significantly, though there is a distinct difference of trend which we will discuss separately

After analyzing the results through the concept of 'openness' index as defined earlier, we conclude that the identity components of an individual are indeed decisive in defining the nature of the network around that 
person.

For doing the regression analysis, we have coded the sub-populations in each in identity category as follows:

- Religion: hindu $=1$, other $=0$.

- Caste: general $=1$, other $=0$.

- income $=0,1,2,3$.

- Gender: male $=1$, other $=0$.

The regression analysis that was done for all four kinds of openness (Table 4) shows us that

1. The regression performance is best in the case of religion openness, followed by income, but is poor in case of gender and caste.

2. In case of religion openness, all the independent variables are significant, the most significant being caste. Here the dependent variable has a negative relation with all the independent variables, the gender score, religion score, income score and caste score.

3. In case of gender, the caste is not significant. Here there is positive relation with gender score and negative with all others.

4. In income, religion and gender are the most insignificant, the others being moderately significant. Here, negative relation with income and positive with all others.

5. In caste, religion and income are very significant, the others being highly insignificant. Here we see positive relation with gender and negative with all others.

\begin{tabular}{|l|l|l|l|}
\hline & Gender (Male vs Others) & Caste (General Caste vs Others) & Income (High vs Low) \\
\hline D-stat & 0.475733064 & 0.281097561 & 0.227865477 \\
\hline p-value & $1.7297 \mathrm{E}-06$ & 0.022592179 & 0.10678017 \\
\hline D-crit & 0.244543398 & 0.254979123 & 0.18826143 \\
\hline size 1 & 92 & 82 & 47 \\
\hline size 2 & 43 & 40 & 62 \\
\hline
\end{tabular}

Table 3: Kolmogorov-Smirnoff Tests

\begin{tabular}{|l|l|l|l|l|l|l|l|}
\hline Dep Var () openness & \multicolumn{5}{|c|}{ Coefficient (s.e.) } & & \\
\hline & Religion & Gender & Income & Caste & Intercept & $R^{2}$ & F (df) \\
\hline Religion & -0.2533 & -0.1569 & -0.2473 & -3.1861 & 1.2319 & 0.4718 & 20.7742 \\
\hline & 0.2492 & 0.1080 & 0.2393 & 0.3866 & 0.4325 & & 93 \\
\hline Gender & -0.2658 & 0.2223 & -1.7604 & -0.0781 & 0.3961 & 0.1701 & 4.7679 \\
\hline & 0.4327 & 0.1875 & 0.4155 & 0.6712 & 0.7510 & & 93 \\
\hline Income & 0.0476 & -0.0508 & 0.1611 & 0.1661 & 0.5227 & 0.0026 & 0.0611 \\
\hline & 0.3943 & 0.1708 & 0.3786 & 0.6116 & 0.6843 & & 93 \\
\hline Caste & -0.7175 & 0.0120 & -0.64 & -0.0939 & -1.203 & 0.065 & 1.6163 \\
\hline & 0.3629 & 0.1572 & 0.3485 & 0.5629 & 0.6298 & & 93 \\
\hline
\end{tabular}

Table 4: Regression Table

We have generated the histograms of the openness indices for each of the identity category we have dealt with. The histograms tell us the way in which the sub-populations within any identity category are different in openness towards that specific identity category. Histogram $1 \mathrm{a}$ and $1 \mathrm{~b}$ shows us the difference in gender openness between male and non-male subgroups of the population. It can be clearly seen that the males are much less open than their female or other counterparts as long as allowing people of other gender identities 


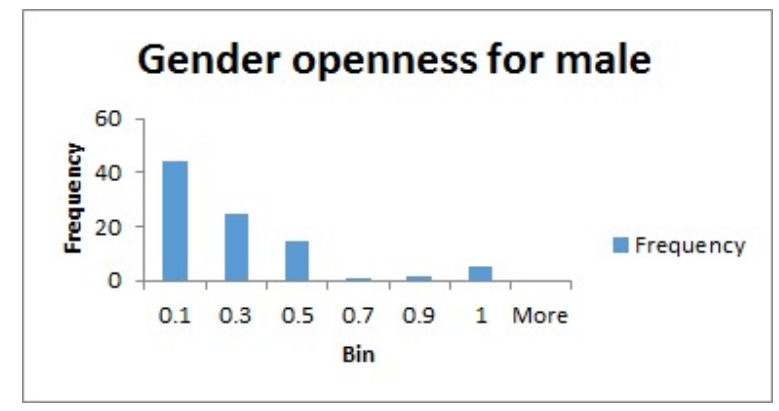

(a) Gender Openness - Male

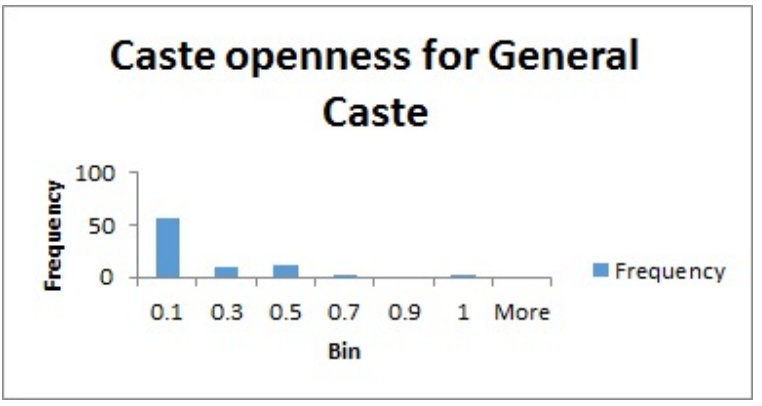

(c) Caste Openness - General Caste

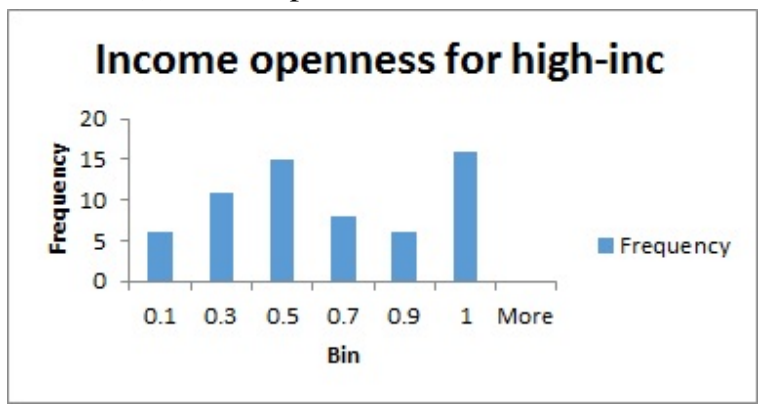

(e) Income Openness - High

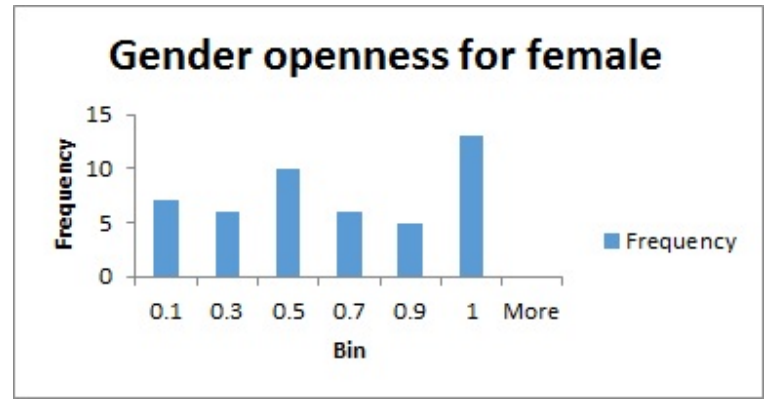

(b) Gender Openness - Female

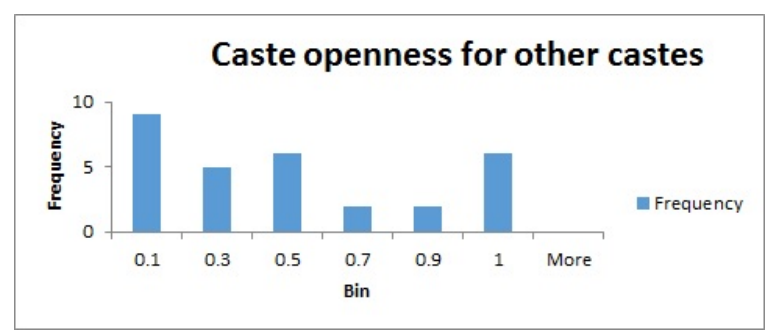

(d) Caste Openness - Other Castes

\section{Income openness for low-inc}

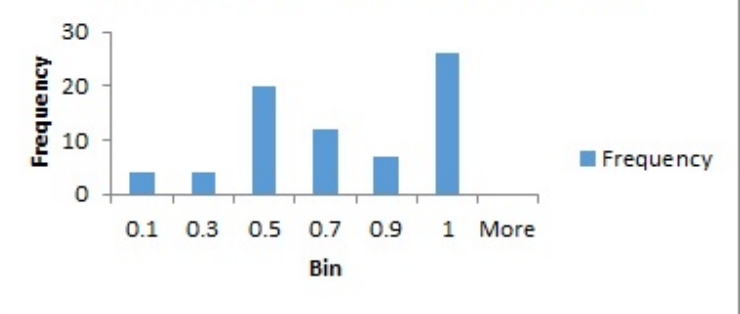

(f) Income Openness - Low

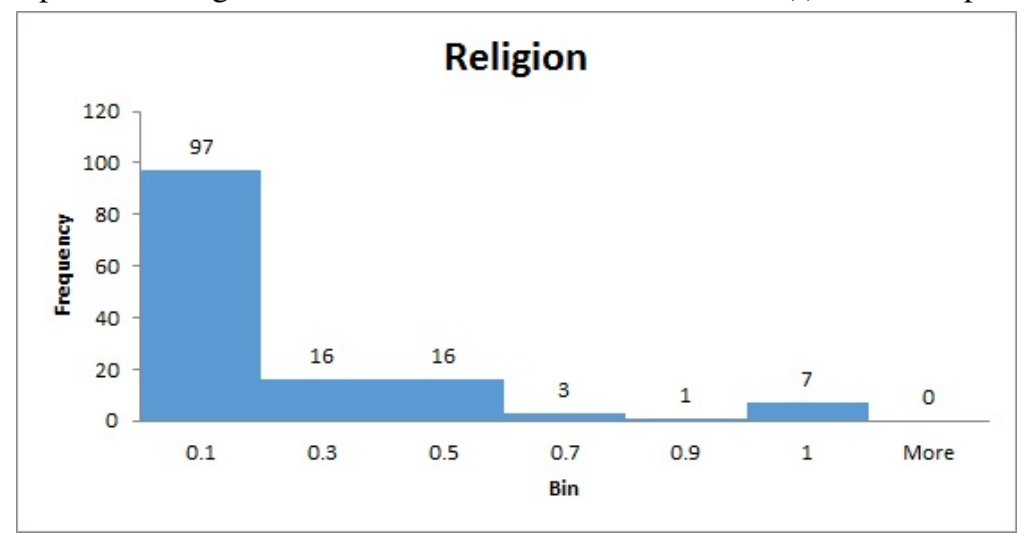

(g) Religion Openness

Figure 1: Histograms 
into one's network is concerned. Similarly, in Histogram 1c and1d, we see that the people who belong to the general caste category are much more reluctant than the people of other caste category to mingle with people belonging to some caste category that is other than their own. In religion, we didn't have enough non-hindu population to compare the histogram between hindu and non-hindu people, but from Histogram 1g, we can see that overall religious openness is severely low throughout the population. As far as openness towards income group is concerned, Histogram 1e and 1f tells us that there is a distinct difference in the behavior of the low income group people and their high income group counterparts. The high income group people are tending to be less tolerant in allowing low income group in their network, while low income group people are slightly better in accommodating high income group people in their network. Although, this difference in the case of income group is not statistically significant within our sample population.

A common trend that we can essentially locate from the histograms is, in a society that is dominated by hindu, upper caste, upper class male representatives, the further people are from such normative combination of identities, the more accommodative they are in including their "socially higher" counterparts within their network. As for the case of gender, historically the "second sex", ie. females, and the "third sex", i.e. LGBT population are seen to be much open in including males into their network whereas males are quite reluctant in 'diluting' their all-male network. Similarly for the case for caste and income group. We believe there is a distinct and characteristic dynamics for such behavior of low openness of 'higher' identities and high openness for 'lower' identities. We are working towards formalizing the dynamics.

Moreover, as we have asked our respondents to identity five most important persons in their friendship, professional and neighborhood network, it is evident that the persons who are most 'open', naturally is alienated from the network comprised of people of its own identity. Hence, as Granovetter showed, there is a high probability that this abundance of weak links in that person's network will change the affiliative identity of that person by the virtue of being in the network of people with 'higher' identity. E.g. being in a group of highly influential persons increases the probability of getting a better job than others who do not belong in that network. It increases the probability of shifting the identity within the income group category. This way, the network a person forms, in turn changes the identity of the person also.

Thus, it can be concluded from the histograms and the statistical tests that the identity of a person essentially and decisively determines the network built around that person and the role of identity in shaping the nature of the network is not at all random, rather quite systematic. We will be formulating an Evolutionary game in our next paper to substantiate our claim of the systematic interaction between societal hierarchy of identities and human social network formation. 


\section{Bibliography}

Akerlof, G. A. and Kranton, R. E. (2000). Economics and identity. Quarterly journal of Economics, pages $715-753$.

Bourdieu, P. (2011). The forms of capital.(1986). Cultural theory: An anthology, pages 81-93.

Burt, R. S. (2009). Structural holes: The social structure of competition. Harvard university press.

Coleman, J. S. (1988). Social capital in the creation of human capital. American journal of sociology, pages S95-S120.

De Graaf, N. D., De Graaf, P. M., and Kraaykamp, G. (2000). Parental cultural capital and educational attainment in the netherlands: A refinement of the cultural capital perspective. Sociology of education, pages 92-111.

DiMaggio, P. (1982). Cultural capital and school success: The impact of status culture participation on the grades of us high school students. American sociological review, pages 189-201.

Dumais, S. A. (2002). Cultural capital, gender, and school success: The role of habitus. Sociology of education, pages $44-68$.

Emirbayer, M. and Williams, E. M. (2005). Bourdieu and social work. Social Service Review, 79(4):689-724.

Emmison, M. and Frow, J. (1998). Information technology as cultural capital.

Fryer, R. (2003). An economic approach to cultural capital. manuscript. University of Chicago.

Goldthorpe, J. H. (2007). ” cultural capital”: Some critical observations. Sociologica, 1(2):0-0.

Granovetter, M. S. (1973). The strength of weak ties. American journal of sociology, pages 1360-1380.

Harker, R. (1990). Education and cultural capital in harker, r., mahar, c., \& wilkes, c.(eds.).(1990). An Introduction to the Work of Pierre Bourdieu: the Practice of Theory.

King, A. (2000). Thinking with bourdieu against bourdieu: A'practical'critique of the habitus. Sociological theory, 18(3):417.

Lin, N., Cook, K. S., and Burt, R. S. (2001). Social capital: Theory and research. Transaction Publishers.

Putnam, R. (2000). Bowling alone: The collapse and revival of community in america. Simon and Schuster, New York, 389:378-390.

Resnick, P. (2001). Beyond bowling together: Sociotechnical capital. HCI in the New Millennium, (77):247272.

Stanton-Salazar, R. D. and Dornbusch, S. M. (1995). Social capital and the reproduction of inequality: Information networks among mexican-origin high school students. Sociology of education, pages 116-135.

Sullivan, A. (2001). Cultural capital and educational attainment. Sociology, 35(04):893-912.

Throsby, D. (1999). Cultural capital. Journal of cultural economics, 23(1-2):3-12.

Williams, D. (2006). On and off the net: Scales for social capital in an online era. Journal of ComputerMediated Communication, 11(2):593-628. 